\title{
Anisotropic path modeling to assess pedestrian- evacuation potential from Cascadia-related tsunamis in the US Pacific Northwest
}

\author{
Nathan J. Wood • Mathew C. Schmidtlein
}

Received: 7 July 2011/Accepted: 23 September 2011/Published online: 16 October 2011

(C) The Author(s) 2011. This article is published with open access at Springerlink.com

\begin{abstract}
Recent disasters highlight the threat that tsunamis pose to coastal communities. When developing tsunami-education efforts and vertical-evacuation strategies, emergency managers need to understand how much time it could take for a coastal population to reach higher ground before tsunami waves arrive. To improve efforts to model pedestrian evacuations from tsunamis, we examine the sensitivity of least-cost-distance models to variations in modeling approaches, data resolutions, and travel-rate assumptions. We base our observations on the assumption that an anisotropic approach that uses path-distance algorithms and accounts for variations in land cover and directionality in slope is the most realistic of an actual evacuation landscape. We focus our efforts on the Long Beach Peninsula in Washington (USA), where a substantial residential and tourist population is threatened by near-field tsunamis related to a potential Cascadia subduction zone earthquake. Results indicate thousands of people are located in areas where evacuations to higher ground will be difficult before arrival of the first tsunami wave. Deviations from anisotropic modeling assumptions substantially influence the amount of time likely needed to reach higher ground. Across the entire study, changes in resolution of elevation data has a greater impact on calculated travel times than changes in land-cover resolution. In particular areas, land-cover resolution had a substantial impact when travel-inhibiting waterways were not reflected in small-scale data. Changes in travel-speed parameters had a substantial impact also, suggesting the importance of public-health campaigns as a tsunami risk-reduction strategy.
\end{abstract}

Keywords Tsunami $\cdot$ Evacuation $\cdot$ Least-cost distance $\cdot$ Modeling $\cdot$ Pedestrian $\cdot$ Cascadia

\footnotetext{
N. J. Wood $(\bowtie)$

Western Geographic Science Center, U.S. Geological Survey, 1300 SE Cardinal Court, Bldg. 10, Vancouver, WA 98683, USA

e-mail: nwood@usgs.gov

M. C. Schmidtlein

Department of Geography, Sacramento State University, 6000 J Street, Sacramento, CA 95819-6003, USA

e-mail: schmidtlein@csus.edu
} 


\section{Introduction}

The tragic loss of life associated with recent catastrophic tsunamis (e.g., 2004 Indian Ocean, 2006 Java, 2009 Samoa, 2010 Chile, 2010 Sumatra, and 2011 Japan) has raised global awareness of tsunami hazards. In many parts of the world, near-field tsunamis could inundate nearby coastal communities only minutes after a damaging earthquake. Evacuations to higher ground are more likely to be on foot than via cars, due to the probable earthquake damage to roads (e.g., road cracking, sand boils, and downed power lines crossing roads) and the high traffic congestion on the remaining working roads.

Successful pedestrian evacuations are possible in some areas given the short distances that at-risk individuals would need to cover to reach high ground (assuming that they recognize natural cues of imminent tsunamis, are capable of self-initiating an evacuation, and know where to go). In areas where at-risk individuals need to traverse significant distances in short time periods, alternatives to horizontal evacuations may be needed to protect lives, such as vertical-evacuation structures or engineered berms. In deciding if and where vertical-evacuation strategies are needed, decision makers require information on the ease with which their citizens and tourists can evacuate on their own to naturally occurring high ground.

Efforts to model pedestrian evacuations from tsunamis have included least-cost-distance (LCD) models and agent-based models. The two approaches need not be exclusive of each other and ideally, a mixed-methods approach could be applied to fully appreciate the complex nature of pedestrian evacuations. LCD models use geographic information system (GIS) tools to calculate the shortest path to safety from every location in a hazard zone, with the difficulty of traveling through each location represented as a cost surface (e.g., time, energy expenditure) based on static landscape considerations (e.g., slope and land cover). Agent-based models incorporate dynamic travel costs due to route capacity, evacuee crowding, and congestion when determining the travel speed and locations of the simulated evacuees (i.e., the agents) (e.g., Jonkmann et al. 2008; Yeh et al. 2009).

Although both LCD and agent-based models can provide useful information for tsunami-evacuation planning, this paper focuses on LCD methods for several reasons. Several critical inputs for agent-based modeling are difficult to constrain for tsunami-evacuation studies, including the magnitude and location of a mixed population (e.g., residents, employees, and tourists), wave-arrival times (given the wide range in earthquake source parameters), and pedestrian interactions on a post-earthquake landscape. Therefore, agentbased models may best serve practitioners who are developing preparedness strategies for a specific tsunami scenario. In these situations, modelers can make a series of input assumptions (e.g., time of day, time of the year, time of wave arrival, and population distributions) to generate a highly precise picture of evacuation issues on a landscape. However, emergency managers rarely develop preparedness and education strategies to deal with one specific scenario and often require more general information that is more applicable to a wide range of potential events. Because of the high spatial and temporal variability of coastal populations and the uncertainty in tsunami-wave-arrival times, emergency managers often want evacuation-time information (e.g., maps of travel times) that is independent of population distributions and wave-arrival times and that can be used in general education and preparedness planning. Because our focus is on understanding the spatial distributions of evacuation times, rather than individual evacuee behavior, we focus on LCD approaches in this paper.

The use of LCD approaches to model pedestrian evacuations from tsunamis is a fairly new but growing topic in the literature (e.g., Post et al. 2009; Graehl 2009; Laghi et al. 
2006). There are various ways to develop LCD models to examine pedestrian evacuations, ranging from simple models based solely on distances from a safe zone to more complex models that incorporate variations in types of land cover and in land-surface slope. To date, when land-surface slope has been included in tsunami-evacuation models, it has been represented as an isotropic constant, meaning the direction of movement on that slope is ignored (e.g., travel costs of running up a hill are considered the same as running down the hill). In addition, travel-time calculations have been based on cost-distance algorithms that calculate the straight-line, horizontal distance between points on a surface, instead of the more appropriate path-distance algorithms that calculate the actual, trigonometric distances between cells of varying elevations.

The objective of this paper is to quantify and discuss the sensitivity of tsunami-evacuation times to various LCD modeling approaches and then to describe an anisotropic approach that incorporates slope directionality and path-distance algorithms. Of existing LCD approaches, we believe this approach better reflects conditions of a real-world evacuation as it takes into account landscape characteristics that influence pedestrian movement. In addition, we assess the sensitivity of evacuation modeling to variations in model inputs (e.g., elevation, land cover, travel speeds). To date, there has been little discussion in the literature on how data resolution influences evacuation-model results.

We realize that modeling approaches described here will not perfectly represent an actual evacuation; like all evacuation models, our approach cannot fully capture all aspects of individual behavior and mobility, the dynamic nature of landscapes (e.g., weather conditions, micro-scale land change), or the interaction of individuals and their environment that would influence evacuee movement. Related, we discuss the use and limitations of this work, as well as identifying areas for future research to further evacuation-modeling efforts. As with all modeling efforts, the focus is on helping managers to better frame an issue and to prioritize where more detailed assessments may be warranted. With regard to preparing for future tsunamis, outputs of this research will help inform emergency managers on evacuation challenges for near-field tsunamis, a topic largely undocumented in the United States (National Research Council 2011). As pedestrian-evacuation modeling becomes more common in the tsunami literature, results from this study will help researchers better understand the influence of modeling assumptions and of data choices on model results. The ultimate goal of this research is to help emergency managers and communities prepare themselves for future tsunamis so that the world never again experiences the tragic and potentially unnecessary loss of life from these catastrophic events.

\section{Study area}

Our study of pedestrian-evacuation modeling is set on the Long Beach Peninsula (Fig. 1) in Pacific County on the open-ocean coast of Washington (United States). The Long Beach Peninsula is over $40 \mathrm{~km}$ in length and is surrounded by the Pacific Ocean to the west and Willapa Bay to the east (Fig. 1a). It contains north-south trending dune systems, several inland lakes, and brushland (Fig. 1b). The northern tip of the peninsula includes the Willapa National Wildlife Refuge and Leadbetter Point State Park and the southern portion rises to connect with Cape Foulwheather and the remainder of the larger Olympic Peninsula that comprises western Washington (Fig. 1c). The peninsula contains two incorporated cities (Ilwaco and Long Beach) and several unincorporated communities (e.g., Oysterville, Nahcotta). 
(a)

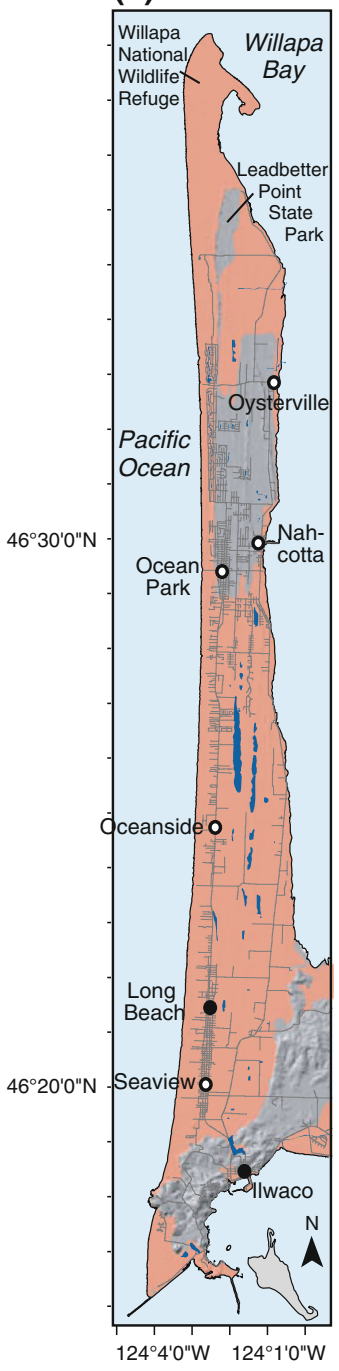

(b)

(c)
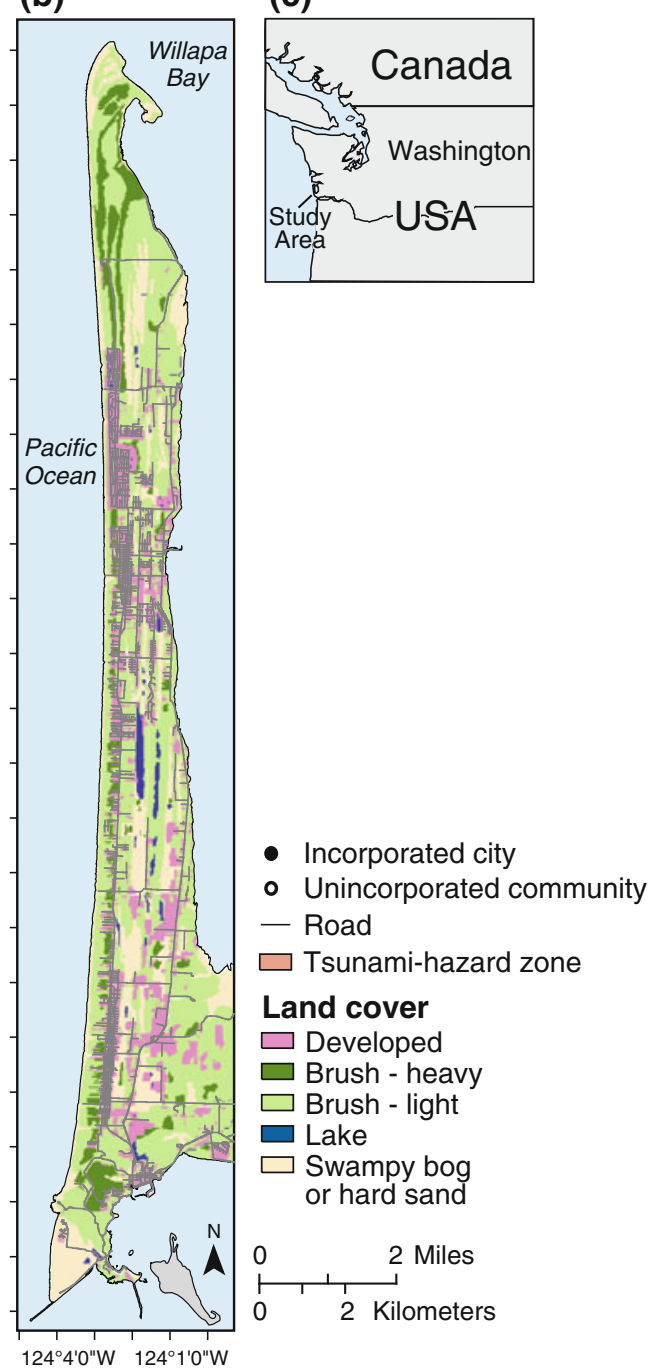

Fig. 1 Maps of the a tsunami-hazard zone on the Long Beach Peninsula, Washington, b land cover of the study area based on manual interpretation of 1-m imagery, and c the study area relative to the State of Washington, United States of America (USA)

We chose the Long Beach Peninsula because local and State emergency managers there already question the ability of the local population to evacuate low-lying areas before tsunami inundation occurs related to a Cascadia subduction zone (CSZ) earthquake. In this scenario, a magnitude 8 or greater earthquake would shake coastal areas for over $3 \mathrm{~min}$, the area would likely subside on the order of 1-2 m, liquefaction of unconsolidated sediment would create sand boils on cracked paved surfaces, and the first of several large tsunami waves would arrive within 20-30 min after the initial earthquake and inundate the majority of the peninsula (Fig. 1a; Walsh et al. 2000). Road networks would likely be compromised for vehicle-based evacuations due to cracked roads, sand boils, and downed electrical lines 
(Cascadia Region Earthquake Workgroup 2005). Tsunami-prone areas of Long Beach Peninsula contain thousands of residents and employees, as well as several public venues, hotels and restaurants, dependent-care facilities, and critical facilities (Wood and Soulard 2008). Disseminating effective tsunami-warning messages from the National Oceanic and Atmospheric Administration (NOAA) West Coast and Alaska Tsunami Warning Center to individuals in low-lying areas before the first wave arrives will be difficult, given the short time between the generation and shoreline arrival of tsunamis associated with a Cascadia earthquake and the great distances that people will need to travel to evacuate (National Research Council 2011). Tsunami education in the region therefore emphasizes the need for at-risk individuals to understand that they are in tsunami-hazard zones, to be able to recognize natural cues of imminent tsunamis, and to know how to evacuate on their own. The pedestrian-evacuation modeling described in this paper was conducted to help further community-based discussions that began in 2010 in this area to explore tsunami verticalevacuation options (Engstfeld et al. 2010).

\section{Methods}

Least-cost-distance models are based on the development of a spatial matrix of cells organized into rows and columns (also known as a raster) where each cell contains a value representing the difficulty, or cost, of movement across a landscape. Various methods for modeling pedestrian travel costs have been proposed, including travel time (Laghi et al. 2006), probability functions based on existing routes (Pingel 2009), and energy expenditure (Jobe and White 2009). We focus on developing a cost surface of travel times because we are interested in understanding whether individuals could evacuate an area before tsunami waves arrive.

\subsection{Tsunami-hazard zone}

The tsunami-hazard zone used in this study (Fig. 1a) is based on scenario 1A (with and without areas on the fault that are stuck, also known as asperities) in Walsh et al. (2000), which denotes a magnitude $\left(M_{\mathrm{w}}\right) 9.1$ earthquake along the CSZ. Sources of error in the inundation modeling are discussed in detail in Priest et al. (1997), but the largest source of uncertainty is in the earthquake parameterization (Walsh et al. 2000). Inundation modeling propagates the limitations of the input bathymetric and topographic data, resulting in horizontal resolution errors of up to $50 \mathrm{~m}$ (Walsh et al. 2000). Modeled inundation lines were smoothed to account for resolution limitations and to place the inundation near logical topographic boundaries (Walsh et al. 2000; Washington Division of Geology and Earth Resources 2008). The safe zone used in this study is any land in the study area, denoted by a shoreline layer (Washington Department of Ecology 2009) that is not in the tsunami-hazard zone (Fig. 1a). Due to hazard-modeling limitations, LCD calculations of the minimum distance from each cell just inside the safe zone to every point outside are therefore first approximations of travel times. The first tsunami wave is predicted to arrive at the study area approximately 25 min after a CSZ earthquake (Walsh et al. 2000).

\subsection{Model comparison}

We used four approaches to examine the influence of modeling approaches on tsunamievacuation potential, including (1) an unconstrained approach involving horizontal 
distance on a flat surface, (2) a horizontally constrained approach involving the road network, (3) an isotropic approach that incorporates land-cover conditions and vertical slope characteristics to accommodate travel outside of the road network, and (4) an anisotropic approach that incorporates land-cover conditions and slope, but additionally takes into account slope directionality (e.g., going uphill is slower than going downhill). In each case, a LCD surface was generated which represents the minimum distance from the safe area to each location in the hazard zone. The distance surfaces were converted to travel-time grids using a base travel speed of $1.1 \mathrm{~m}$ (3.5 feet) per second. This speed represents the 15th percentile of walking speeds of a mixed population and is the recommended speed for crosswalk walking speed standards in the United States (United States Department of Transportation 2009). Unlike previous efforts (Laghi et al. 2006; Anguelova et al. 2010), we converted least-cost-distance surfaces to travel times after LCD geoprocessing, giving us greater flexibility to modify travel rates. For the purposes of this analysis, we assume that pedestrian fatigue is minimal and travel speeds remain constant. This is a simplification of actual travel, especially for younger and older evacuees, and additional physiological research is needed to better quantify the relationship between travel distances and fatigue given the land-cover conditions in our study area.

\subsubsection{Distance-only approach}

The first evacuation model estimates travel times by calculating the shortest path, regardless of land-cover conditions or slope, from cells in safe areas to cells in the tsunamihazard zone using ArcMap's Cost Distance tool (ESRI 2009a). The only data required for this is a raster that denotes whether or not cells are in the hazard zone.

\subsubsection{Road-constrained approach}

The second evacuation model also is based on horizontal distances without regard to slope and land-cover variations, but confines travel to road networks (an approach used in many agent-based tsunami-evacuation models). This approach uses cost-distance geoprocessing of the same raster grids as before that delineate safe zones and hazard zones but also includes a county roads layer (Pacific County Department of Public Works 2010). This approach assumes pedestrians will travel to the closest road and then stay on roads to leave the hazard zone. To model this, we added the cost-distance from each location to the nearest road and a cost-distance calculation along the constrained-route of the roadway network from that location to the nearest area outside the hazard zone.

\subsubsection{Isotropic approach that incorporates slope and land cover}

The third evacuation model also uses cost-distance geoprocessing but does not constrain travel to roads and includes the influence of variable slope and land-cover types (e.g., IMELS 2006; Laghi et al. 2006; Post et al. 2009). We reclassified land-cover and slope data into "speed conservation value" (SCV) surfaces that represent the percentage of maximum travels speed that would occur on a given land cover or slope. For example, if a pedestrian's maximum travel speed is assumed to be on a road, the travel speed on any other land-cover surface would be some smaller percentage. This resulted in a SCV raster surface for land cover and another SCV surface for slope. The ArcMap Map Algebra tool was used to multiply these two surfaces together, creating a slope/land-cover SCV for each 
grid cell. We then used the inverse of the composite SCV as the input to the Cost Distance tool, and multiplied the resulting surface by the inverse of the base travel speed.

Slope SCV for each grid cell is based on the maximum slope in the cell, based on a 1-m digital elevation model (DEM) derived from Light Detection And Ranging (LiDAR) remotely sensed technology (WatershedSciences 2010). Various slope relationships have been used in previous evacuation studies. Some studies do not document their slope relationships (e.g., IM-ELS 2006; Laghi et al. 2006). Studies that document these relationships can be broadly classified into two categories: "hiking functions" that can be used to estimate travel rates for given slope values, and "range estimates" that give a set of travel rates for set ranges of slopes. We dismissed range estimates (e.g., Post et al. 2009; Butler et al. 2000; Anguelova et al. 2010; Graehl 2009) which would unnecessarily introduce a generalization to slope calculations. We also dismissed hiking functions that are not empirically based (as discussed in Fritz and Carver 1998; Norman 2004; Scarf 1998). An approach proposed by Hayes (described in Norman 2004) is empirically based but is based on wilderness runner data and we assume many evacuees will be incapable of running because of age, health, or other mobility issues (e.g., parents carrying children). Therefore, we used the empirically based relationship of slope and walking speed of hikers as described in Tobler (1993):

$$
\text { Walking speed }=6 \mathrm{e}^{-3.5 \times \mathrm{abs}(\text { slope }+0.05)}
$$

Speeds were then converted into SCVs by dividing them by the maximum potential walking speed, which is a universal calculation across the full extent of the slope-based, walking-speed surface. Slope SCV for each grid cell is based on the maximum slope in the cell rather than the slope along the direction of movement. This isotropic or non-directional treatment of slope means that the influence of slope on movement through the cell is the same regardless if the movement is uphill, downhill, or parallel to contour lines.

Various relationships have been used to equate land-cover type and walking speeds. Expert judgment has been used to reclassify land-cover layers into SCV surfaces in several studies (Anguelova et al. 2010; Laghi et al. 2006; Post et al. 2009). Jobe and White (2009) describe appropriate land-cover costs based on pedestrian energy expenditure but lack actual SCV for land-cover classes. We developed SCV values using the inverse of Soule and Goldman's (1972) energy cost terrain coefficients for certain land-cover types (Table 1). This approach assumes walking speeds will decrease in proportion to the changes in energy required to move across different land-cover types. We recognize that this is a simplification of the actual processes involved; however, no existing empirical research could be identified that related relevant land-cover types to pedestrian walking speeds. This approach therefore seemed most appropriate until field-derived relationships can be developed. A land-cover SCV layer was then created using this classification scheme and a manual interpretation of land cover from 2009 1-m pixel resolution, orthorectified color imagery provided by the U.S. National Agriculture Imagery Program (United States Department of Agriculture 2009).

Prior to assigning SCV values, we superimposed a road layer (Pacific County Department of Public Works 2010) and a buildings layer extracted from the 1-m DEM using methods described in Hewett (2005) on top of the 1-m land-cover layer. Areas with buildings were considered impassable to pedestrians, as well as not viable vertical-evacuation destinations because of the predicted size and power of tsunami waves relative to the typical one- to two-story wood buildings that dominate the study area. Cells classified as water also were considered impassable. Building footprints and water areas were 
Table 1 Relationships between National Land Cover Database (NLCD) land-cover classes and terrain categories and coefficients for energy cost prediction from Soule and Goodman (1972)

\begin{tabular}{llll}
\hline NLCD code & NLCD description & $\begin{array}{l}\text { Soule and Goldman } \\
\text { categories }\end{array}$ & $\begin{array}{l}\text { Speed conservation value } \\
\text { (proportion of maximum } \\
\text { travel speed) }\end{array}$ \\
\hline & Roads & Blacktop & 1 \\
11 & Open water & None & 0 \\
21 & Developed, open space & Dirt road & 0.9091 \\
23 & Developed, low intensity & Dirt road & 0.9091 \\
24 & Developed, medium intensity & Dirt road & 0.9091 \\
31 & Developed, high intensity & Dirt road & 0.9091 \\
41 & Barren land & Hard sand & 0.5556 \\
42 & Deciduous forest & Light brush & 0.8333 \\
43 & Evergreen forest & Light brush & 0.8333 \\
52 & Mixed forest & Light brush & 0.8333 \\
71 & Shrub/scrub & Heavy brush & 0.6667 \\
81 & Grassland/herbaceous & Light brush & 0.8333 \\
82 & Pasture/hay & Light brush & 0.8333 \\
90 & Cultivated crops & Light brush & 0.8333 \\
95 & Woody wetlands & Swampy bog & 0.5556 \\
\hline
\end{tabular}

modeled as impassable by setting the SCV values to "NoData" at these locations during the manual land-cover interpretation. Roads were considered to have the maximum travel speed (i.e., a SCV of 1.0 in Table 1). We used the "Dirt Road" category in Soule and Goldman (1972) to categorize developed areas other than roads and buildings because it seemed likely that the mix of other land-cover elements in these areas (e.g., landscaping) would provide some additional impedance but not, on average, a substantial one.

\subsubsection{Anisotropic scenario that incorporates slope and land cover}

The fourth model incorporates land-cover data using the isotropic approach to generate a land-cover SCV as described earlier but an anisotropic approach to calculating the impact of slope directionality on travel costs. Although new to tsunami-evacuation modeling, anisotropic approaches have been used to model pedestrian accessibility to wilderness areas (e.g., Jobe and White 2009), pedestrian mobility in relation to wildfire risk (Anguelova et al. 2010), or route reconstruction in anthropological studies (Pingel 2009). Because of the inclusion of slope directionality, travel distances are calculated using Path Distance geoprocessing (ESRI 2009b) instead of the cost-distance approach described earlier and in other studies (IM-ELS 2006; Laghi et al. 2006). The Path Distance tool is more appropriate because it allows for both the calculation of three-dimensional distances between cells of varying elevations, as well as the path of travel from a given cell to each of its neighbors from which the slopes along the path can be calculated.

To calculate anisotropic costs based on slopes, we used the 1-m DEM to calculate the slope between a given focal cell and each of its neighbors. This slope is then used to retrieve the anisotropic cost from a lookup table that contains inverse slope SCV derived from Tobler's hiking function-with one important modification. We reversed the 
direction of slope values in the table (i.e., changed positive slopes to negative, and negative slopes to positive) because LCD calculations begin at the safety zones and expand outward into a hazard zone. Therefore, the search direction and slope of the Path Distance tool (from safety to danger) is the opposite of the direction of evacuation (from danger to safety) — what was downhill in the search algorithm would be uphill to an evacuee. Similar to the other approaches, the final least-cost-distance surface is then multiplied by the inverse of the base travel rate to calculate a least evacuation-time surface.

\subsection{Data sensitivity}

We tested the sensitivity of the anisotropic approach to varying resolutions of elevation and land-cover data to help researchers and emergency managers understand where to devote limited resources in future efforts. Elevation-data sensitivity was examined by comparing model runs using a 1-m DEM (WatershedSciences 2010) and a 10-m resampling of the same data, which replicates a common product of the National Elevation Dataset (NED) (Gesch et al. 2009). Land-cover-data sensitivity was examined by comparing model runs using the 1-m manual interpretation of land cover described earlier with 30-m resolution land-cover data from the 2001 National Land Cover Database (NLCD; U.S. Geological Survey 2008). NLCD data were re-classified to categories from Soule and Goldman's (1972) energy cost terrain coefficients (Table 1) and overlaid with the roads and building footprint layers described earlier. We used the "Dirt Road" category in Soule and Goldman (1972) to categorize NLCD cells classified as developed (i.e., high-, medium-, lowintensity, and open space) but not roads or buildings for similar reasons described for the 1-m land-cover layer. When comparing the land-cover data, we disaggregated the $30-\mathrm{m}$ NLCD data down to $10-\mathrm{m}$ cells to match the elevation data. We recognize that this resolution is at a finer level than the input imagery, but felt that doing so allowed us to better preserve the more detailed elevation data. Comparative-analysis results should be interpreted with this caveat in mind.

\subsection{Travel speeds}

As discussed earlier, we used a base travel speed of $1.1 \mathrm{~m} / \mathrm{s}$ in our comparison of modeling approaches. However, at-risk populations in tsunami-prone areas will vary in their mobility and ability to travel long distances in short time periods. To provide a more realistic assessment of evacuation potential and to test model sensitivity, we calculated travel times to safety by varying travel-speed assumptions but keeping constant the modeling approach (anisotropic) and data resolution (1-m elevation and 1-m land cover). Running speeds include a fast rate of $3.83 \mathrm{~m} / \mathrm{s}$ (7-min mile), a moderate rate of $2.68 \mathrm{~m} / \mathrm{s}$ (10-min mile), and a slow rate of $1.79 \mathrm{~m} / \mathrm{s}$ (a 15-min mile) based on a review of race results from the 2010 Boston Marathon (MarathonGuide.com 2011). Walking speeds include a fast rate of $1.52 \mathrm{~m} / \mathrm{s}$ (Knoblauch et al. 1995b), a moderate rate of $1.22 \mathrm{~m} / \mathrm{s}$ (U.S. Department of Transportation 2009; Langlois et al. 1997), and a slow rate of $0.91 \mathrm{~m} / \mathrm{s}$ (Knoblauch et al. 1995a; Langlois et al. 1997; Fitzpatrick et al. 2006).

\subsection{Population exposure}

To communicate the impact of the various evacuation-modeling approaches on the safety of at-risk populations, we assembled three population datasets. A resident-population point 
file was created by manually identifying residential structures in the 2009 NAIP color imagery and then disaggregating population counts in the 2010 U.S. Census Bureau population count at the block level (U.S. Census Bureau 2011) to structures (e.g., 20 structures in a census block with 100 people were each allocated five people). Populations that are under 5 years and over 65 years in age were identified in the 2010 Census Bureau block data to highlight the ability to incorporate demographic attributes of exposed populations into the evacuation models. While all individuals may have difficulty evacuating tsunami-prone areas, these two age groups may be additionally challenged to pre-event mobility issues. An employee-population point file was developed using a spring 2010 version of the InfoUSA Employer Database (InfoUSA 2010). A third population layer was created using the Employer Database to identify businesses classified as public venues that cater to tourists (e.g., hotels, attractions) or as dependent-population facilities that contain individuals with limited mobility (e.g., child day-care centers, hospitals, adult-residential care centers). Unlike the resident and employee layers, this layer simply denotes the presence of such businesses and not the number of occupants. Each population layer was overlaid on the evacuation-time maps to determine the number of individuals or facilities at various travel times to safety.

\section{Results}

The following section summarizes our analysis of pedestrian-evacuation potential on Long Beach Peninsula, Washington, related to a Cascadia tsunami. We first report on variations in pedestrian travel times to safety when four different least-cost-distance modeling approaches are used. Next, we report on variations in pedestrian travel times to safety when the type and resolution of input data are varied but the modeling approached is identical. Finally, we look at the sensitivity of model results when travel speeds are varied. In each case, we discuss variations in terms of the spatial distribution of travel times and the impact on population exposure relative to travel times.

\subsection{Population exposure to tsunamis based on distance to safety}

Figure 2a portrays the modeled travel times to safety for pedestrians, assuming a constant travel rate of $1.1 \mathrm{~m}$ per second and using the anisotropic approach described in Sect. 3.2.4. Populations in areas colored from orange to black in Fig. 2a would not likely have enough time to evacuate before tsunami arrival (assumed here to be $25 \mathrm{~min}$ after the initial earthquake). These areas represent a substantial portion of the Long Beach Peninsula landscape, specifically the middle of the peninsula near the community of Oceanside (Fig. 1). Mean and maximum travel times to safety across the peninsula are 46 and 133 min, respectively (Table 2). There are approximately 4,244 residents, 477 employees, 40 public venues, and 7 dependent-population facilities at locations that may require 25 min or more of travel time to reach areas outside of the tsunami-inundation zone (Table 2). The distribution of at-risk populations across the peninsula relative to travel times to safety varies depending on population type; for example, there are residential peaks at 10, 30, and $50 \mathrm{~min}$ and employee peaks at 38, 45, and $55 \mathrm{~min}$ to reach safety (Fig. 3a). Of the 4,244 residents that may require $25 \mathrm{~min}$ or more to reach high ground, approximately 1,204 residents are over 65 years in age (28\% of high-risk population) and 171 residents are under 5 years in age (4\% of high-risk population). Of the 40 public venues without sufficient time to reach safety, the majority of them are overnight 
Table 2 Differences in evacuation travel times and potential population exposure to tsunamis based on various modeling approaches and resolutions of input data

\begin{tabular}{|c|c|c|c|c|c|c|}
\hline \multirow[t]{2}{*}{ Anisotropic $^{\mathrm{a}}$} & \multicolumn{3}{|c|}{$\begin{array}{l}\text { Percentage change with } \\
\text { different modeling approaches }\end{array}$} & \multicolumn{3}{|c|}{$\begin{array}{l}\text { Percentage change with different data } \\
\text { resolutions }{ }^{b}\end{array}$} \\
\hline & $\begin{array}{l}\text { Distance } \\
(\%)\end{array}$ & $\begin{array}{l}\text { Roads } \\
(\%)\end{array}$ & $\begin{array}{l}\text { Isotropic } \\
(\%)\end{array}$ & $\begin{array}{l}1-\mathrm{m} \\
\text { elevation } \\
\text { and } 30-\mathrm{m} \\
\text { NLCD }(\%)\end{array}$ & $\begin{array}{l}10-\mathrm{m} \\
\text { elevation } \\
\text { and } 1-\mathrm{m} \text { land } \\
\text { cover }(\%)\end{array}$ & $\begin{array}{l}10-\mathrm{m} \\
\text { elevation } \\
\text { and 30-m } \\
\text { NLCD }(\%)\end{array}$ \\
\hline
\end{tabular}

\begin{tabular}{|c|c|c|c|c|c|c|c|}
\hline \multicolumn{8}{|c|}{ Evacuation travel time (min) } \\
\hline $\begin{array}{l}\text { Average } \\
\text { time }\end{array}$ & 46 & -30 & 0 & -4 & 2 & -63 & -63 \\
\hline $\begin{array}{l}\text { Maximum } \\
\text { time }\end{array}$ & 133 & -24 & 5 & -7 & 4 & -62 & -60 \\
\hline
\end{tabular}

Number of people at 25 min or more travel time

$\begin{array}{lrrrrrrr}\text { Residents } & 4,244 & -13 & 1 & -3 & 0 & -68 & -66 \\ \text { Employees } & 477 & -4 & 1 & 0 & 0 & -86 & -84\end{array}$

Number of facilities at 25 min or more travel time

\begin{tabular}{|c|c|c|c|c|c|c|c|}
\hline $\begin{array}{l}\text { Public } \\
\text { venues }\end{array}$ & 40 & -5 & 5 & 0 & 5 & -80 & -80 \\
\hline $\begin{array}{l}\text { Dependent- } \\
\text { population } \\
\text { facilities }\end{array}$ & 7 & 0 & 0 & 0 & 0 & -71 & -71 \\
\hline
\end{tabular}

${ }^{a}$ Results of the different modeling approaches are based on the use of 1-m elevation and 1-m land-cover data

b Results of the different data resolutions are all based on anisotropic methods. Percentages are relative to variations from using 1-m elevation and 1-m land-cover data (i.e., "anisotropic" column)

accommodations (e.g., hotels, campgrounds) in areas that would require $50 \mathrm{~min}$ or more to reach safety (Fig. 3b). Other venues in areas with significant travel times to safety include religious centers (e.g., churches), attractions (e.g., museums), and schools.

\subsection{Model comparison}

We assume that an anisotropic, path-distance approach to LCD pedestrian-evacuation modeling is the most appropriate approach because it incorporates variations in land cover and the directionality of an evacuation. We therefore present results of the other three models as difference maps (in units of minutes) relative to the anisotropic model results (Fig. 2). In Fig. 2b-d, blue colors identify areas where another model is underestimating likely travel times (e.g., a isotropic calculates travel times to be $20 \mathrm{~min}$ at a location, whereas the anisotropic approach calculates a 30-min travel time). Green colors in Fig. 2b$\mathrm{d}$ identify areas where the other model is overestimating likely travel times (e.g., $30 \mathrm{~min}$ in one model but $15 \mathrm{~min}$ in the anisotropic approach).

Of the three other modeling approaches, the Distance modeling approach deviates the most from the anisotropic results (Fig. 4a). Differences between the two approaches range from none (28\% of study area) up to 50 min (1\% of study area), with the most frequent difference (32\%) being 1-10 min (Fig. 4b). The Distance model consistently underestimates the time needed to evacuate; for example, maximum and average travel times are 24 and 30\% lower, respectively, than the time predicted using the anisotropic approach. These differences translate to $13 \%$ fewer residents and $4 \%$ fewer employees being 
(a)

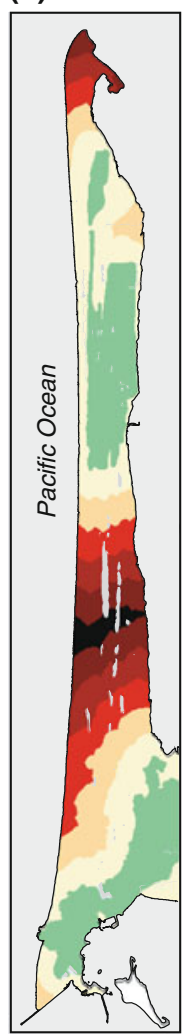

(b)

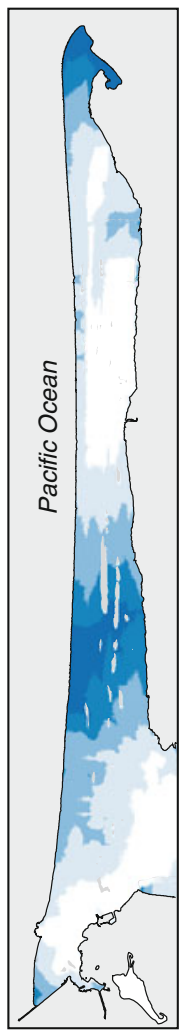

(c)

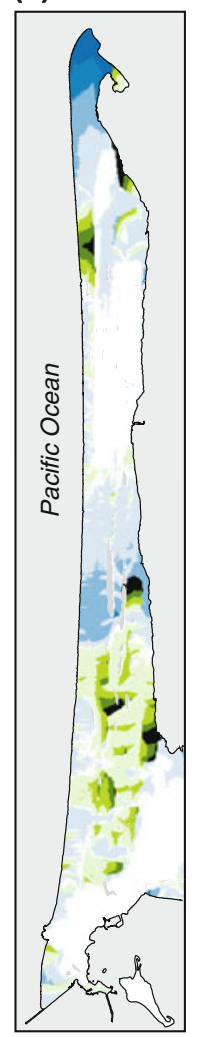

(d)

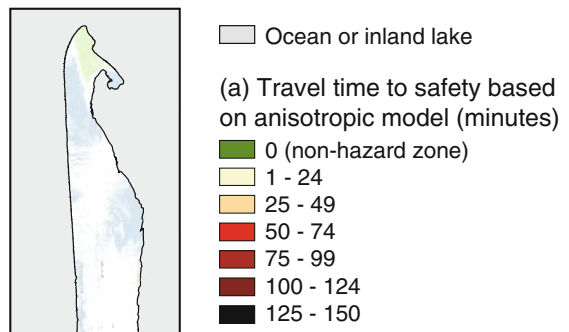

(b - d) Difference between model approaches (minutes)

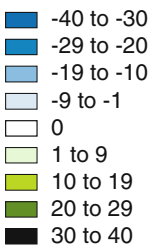

$\stackrel{N}{N}$

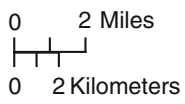

Fig. 2 Maps showing pedestrian travel times across the Long Beach Peninsula, Washington, including a an anisotropic evacuation-modeling approach, $\mathbf{b}$ the difference between a distance approach and the anisotropic approach, $\mathbf{c}$ the difference between a roads approach and the anisotropic approach, and $\mathbf{d}$ the difference between an isotropic approach and the anisotropic approach

(a)

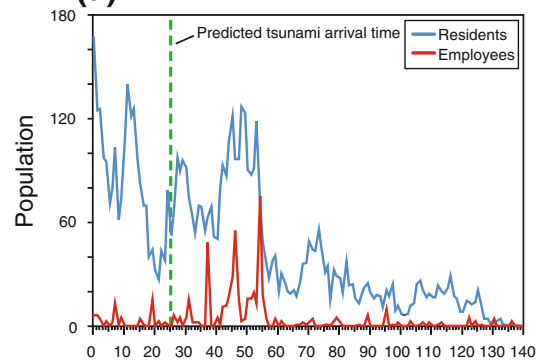

Travel Time to Safe Zone (minutes) (b)

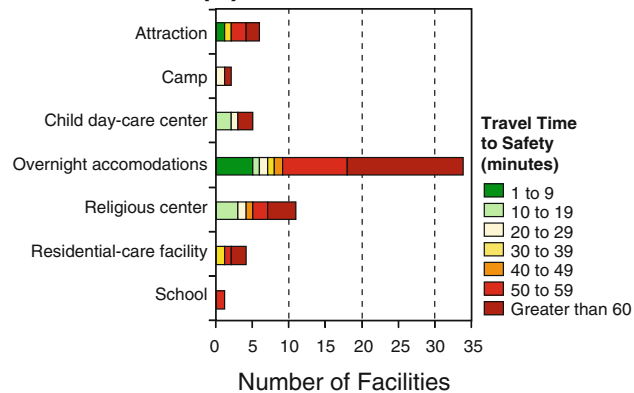

Fig. 3 Distribution of a residential and employee populations and $\mathbf{b}$ public venues and dependent-care facilities on Long Beach Peninsula, Washington, as a function of pedestrian travel times. Modeling is based on anisotropic assumptions and 1-m elevation and 1-m land-cover data 
considered at-risk to tsunami inundation if a Distance model is used (Table 2). However, estimates of residential and employee exposure to tsunamis do not vary greatly at the critical time threshold of 25 min (Fig. 4c, d). The cumulative percentage of the residential population at locations where travel time is $25 \mathrm{~min}$ or less (i.e., people we assume that could evacuate in time) ranges from 54\% (anisotropic model) to $61 \%$ (distance-only model) of the study-area residents (Fig. 4c). Differences at this time threshold are even smaller for employee distributions, where the range in cumulative percentage of employees is only 3\%-from 39\% (anisotropic approach) to $42 \%$ (distance-only approach) (Fig. 4d). Differences in population exposure due to different modeling approaches become much larger at around the 40-min mark-a 16\% difference between anisotropic and distance approaches for residents and a $28 \%$ difference between them for employee distributions. For example, the percentage of employees in the study area at locations where travel time is $44 \mathrm{~min}$ or less range from $54 \%$ of the population (anisotropic model) to $90 \%$ (distance model). Differences in population exposure as a function of travel time between the two models become less substantial $(<5 \%)$ beginning at $55 \mathrm{~min}$ for residents (Fig. 4c) and 60 min for employees (Fig. 4d).

Results of the Road modeling approaches also vary substantially from the anisotropic approach (Fig. 2c) but the differences are not as great (Fig. 4a) or consistent (Fig. 4b). The differences between the two models suggest a normal distribution centered on zero

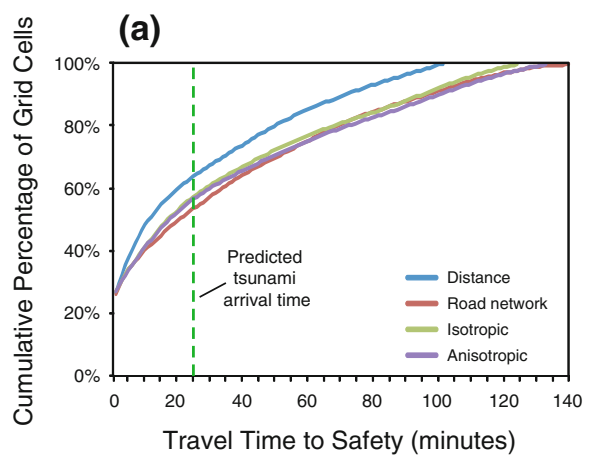

(b)

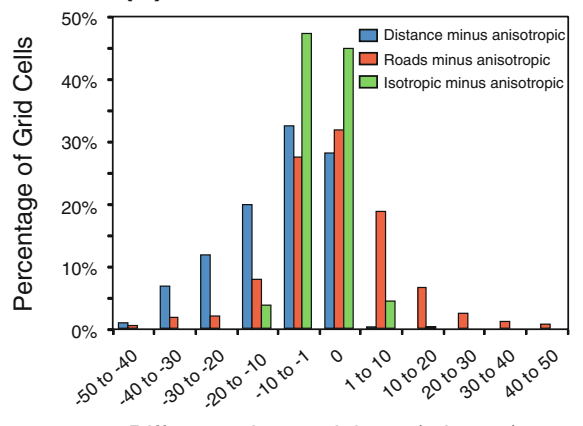

Difference in travel times (minutes)
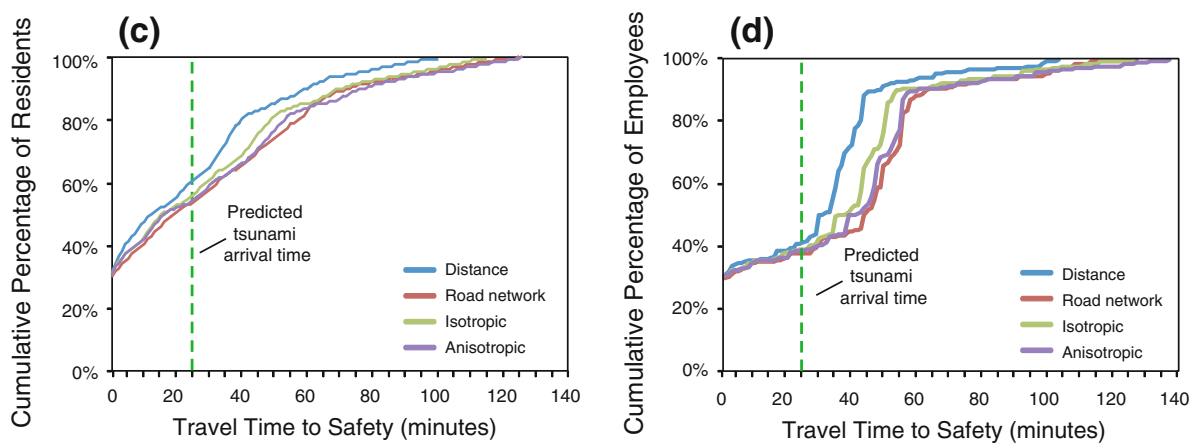

Fig. 4 Graphs showing influence of evacuation-modeling approaches on a the cumulative percentage of grid cells relative to calculated travel times to safety, b differences between evacuation-modeling approaches in travel times to safety, c residential exposure as a function of modeled travel time to safety, and $\mathbf{d}$ employee exposure as a function of modeled travel time to safety 
(i.e., no difference) with approximately $30 \%$ of the study area reporting underestimates of 1-10 min and $20 \%$ of the study area reporting overestimates of 1-10 min (Fig. 4b). Differences in calculated average and maximum evacuation are less than 1 and 5\%, respectively (Table 2). The Road model underestimates the likely time needed to evacuate in some areas (e.g., northern tip and middle of the peninsula) and overestimates travel times in other areas (e.g., near the communities of Oceanside, Long Beach, and west of Oysterville) (Fig. 2c). The overestimates are likely demonstrating how the Roads model forces pedestrians to take longer road-based routes, when shorter non-road routes may be more efficient. This also may reflect an unlikely scenario if pedestrians are forced to travel on roads that lead toward the Pacific Ocean, instead of the intuitive action to move away from shoreline. In many places, the Road model is overestimating travel times by up to $40 \mathrm{~min}$ in areas where anisotropic model results suggest evacuations could be completed in less than $25 \mathrm{~min}$. Although there are identifiable spatial variations in the differences between the anisotropic and Roads modeling approaches (Fig. 2c), the impacts to population exposure estimates are not substantial (Table 2; Fig. 4c, d). The differences between modeling approaches in the number of employees and residents at locations that would require $25 \mathrm{~min}$ or more to evacuate are less than $1 \%$. Similarly, small differences were observed for calculations related to the number of dependent-population facilities and public venues at locations where evacuation will be difficult. Therefore, while the mapped results demonstrate pockets of substantial differences in calculated pedestrian travel times, these areas do not contain substantial populations.

Evacuation times generated by isotropic and anisotropic modeling approaches are fairly consistent (Fig. 4a, b), likely a result of the fairly low relief of our study area. Although differences were observed over much of the study area (Fig. 2d), the majority of the differences were on the order of $1-9 \min (47 \%$ of the study area) with the isotropic approach underestimating travel times (Fig. 4b). Where these small differences matter most are in the areas where every second counts for a successful evacuation, such as the interface of the yellow (1-24 min) and orange zones (25-49 min) in Fig. 2a. At these locations, an underestimation of 9 min could mean the difference between life and death. Although most differences between the two models were confined to only a few minutes, there is an area in the middle of the peninsula where the isotropic model underestimates likely travel times by up to $20 \mathrm{~min}$. Mapped results of the differences between the anisotropic and isotropic indicate a general trend of underestimation by the isotropic approach (e.g., 4 and 7\% lower average and maximum evacuation travel times; Table 2) but these differences do not dramatically impact population exposure estimates (e.g., less than $3 \%$ difference in exposure estimates of residents, employees, public venues, and dependent-population facilities) (Table 2).

\subsection{Data sensitivity}

Varying the resolution of data inputs in anisotropic, path-distance modeling dramatically impacts calculated travel times, as demonstrated by difference maps (with units in minutes) based on various data inputs relative to a model run using the 1-m DEM and 1-m landcover data described earlier (Fig. 5a). In Fig. 5b-d, blue colors identify areas where travel times are underestimated and green colors identify areas where travel times are overestimated by the other model runs. Figure 6 portrays data-resolution comparisons as a function of the cumulative percentage of grid cells at various travel times to safety (Fig. 6a) and cumulative percentages of grid cells relative to differences in modeled time to safety (Fig. 6b). 
(a)

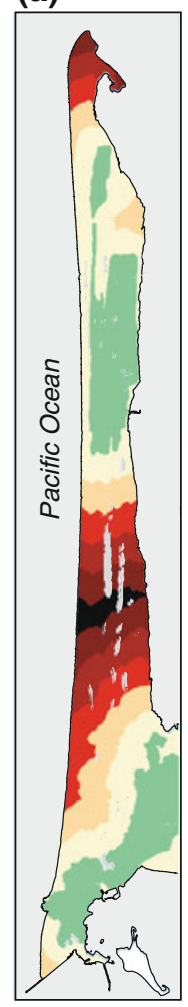

(b)

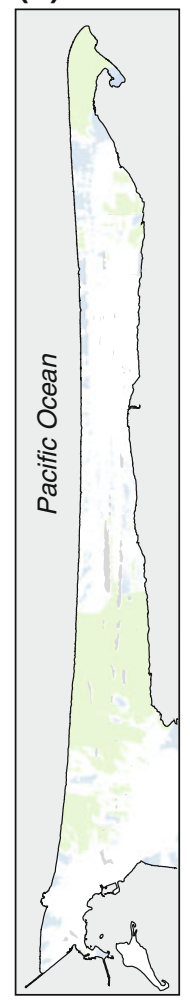

(c)

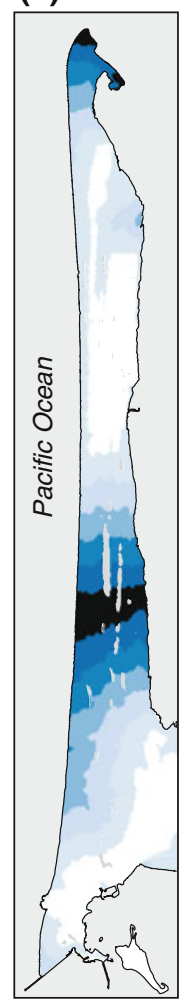

(d)

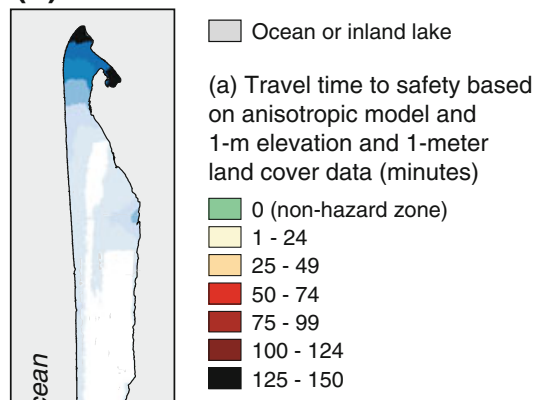

(b - d) Difference in travel times between model runs using 1-m/1-m data (fig. a) and other data resolutions (minutes)

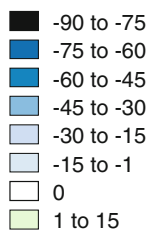

N 0,2 Miles

A 0 2 Kilometers

Fig. 5 Maps showing pedestrian travel times across the Long Beach Peninsula, Washington, based on an anisotropic modeling approach and various data sets. a Shows results of the anisotropic using 1-m elevation data and 1-m land-cover data. b-d Show the difference at each grid cell between a and $\mathbf{b}$ 1-m elevation and 30-m NLCD data, c 10-m elevation and 1-m land-cover data, and d 10-m elevation and 30-m NLCD data

Results suggest that elevation resolution has a much more dramatic impact on modeled pedestrian travel times than land-cover resolution in our study area (Fig. 6a). Profiles of the cumulative percentage of grid cells for models using 1-m elevation but varying the landcover data are fairly uniform. However, when the elevation-data input is changed to the $10-\mathrm{m}$ NED proxy, the profiles of the cumulative percentage of grid cells for both the 1-m manual interpretation of land cover and 10-m disaggregation of NLCD data are drastically different than the original 1-m elevation, 1-m land-cover model results. Regardless of landcover input, the model runs using the $10-\mathrm{m}$ elevation dataset underestimates likely travel times for pedestrians in our study area (Fig. 6a).

Retaining the 1-m elevation data but using the 30-m land cover does create differences in the time required to evacuate but these differences are not widespread or large (Fig. 5b). Fifty percent of grid cells showed no difference in calculated travel times between the two model runs (Fig. 6b). Forty percent of grid cells showed overestimates of up to $15 \mathrm{~min}$ (Fig. 6b) and these grid cells were primarily at the northern tip of the peninsula or in the lower area near the community of Long Beach (Fig. 5b). Approximately $10 \%$ of the grid cells showed underestimates of pedestrian travel times in the range of 1-15 min (Fig. 6b) and these underestimates occur in small pockets of land across the study area (Fig. 5b). 

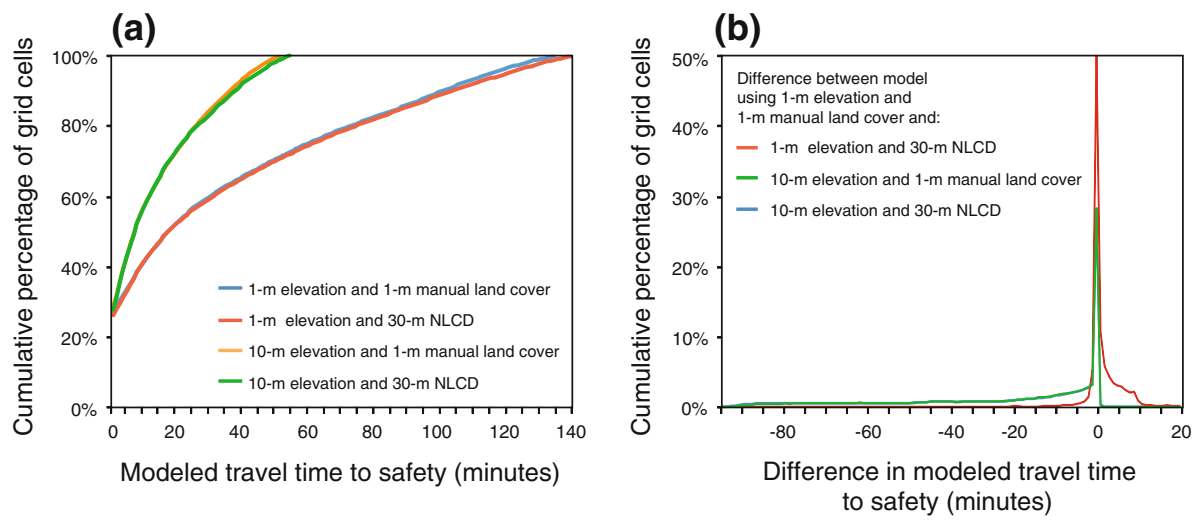

Fig. 6 Graphs showing influence of data resolution on a the cumulative percentage of grid cells relative to calculated travel times to safety, and $\mathbf{b}$ the percentage of grid cells relative to differences in travel times

These pockets are largely associated with areas where small water bodies (e.g., canals, lakes) not captured in the 2001 NLCD land-cover data would influence pedestrian routes to safety, such as west of Oysterville on the northern end of the peninsula (Fig. 7). Across the entire study area, the effect on population exposure estimates from using the NLCD data is minimal-average and maximum evacuation times increase only by 2 and $4 \%$ and the number of residents, employees, public venues, and dependent-population facilities at 25 min or more of travel time show differences that range only from 0 to $5 \%$ (Table 2).

Using a 10-m DEM as the elevation input instead of a 1-m DEM has a dramatic impact on anisotropic modeling of pedestrian-evacuation time to safety. Before summarizing these results, we assert that accompanying variations in land-cover data (i.e., a comparison of Fig. 5c, d) does not drastically change model outputs. Differences exist between model runs (especially in the area of maximum travel times), but in general, the two figures are similar and, as such, we discuss these results at the same time. Approximately $30 \%$ of the grid cells in the study area show no difference between model runs using 1- and 10-m elevation inputs (Fig. 6b). The remaining $70 \%$ of grid cells show underestimates of travel times (i.e., blue colors in Fig. 5c, d) when the coarser-resolution dataset was used (Fig. 6b). Average and maximum evacuation times across the study area were lower by approximately 60-63\% when the 10-m elevation data were used compared to model results based on the 1-m elevation data (Table 2). These differences are also reflected in population exposure estimates, where model runs using the coarser 10-m elevation data undercounted the number of residents (66-68\% of the 1-m model run), employees (84-86\%), public venues $(80 \%)$, and dependent-population facilities $(71 \%)$ at locations that would require $25 \mathrm{~min}$ or more travel time to safety.

\subsection{Travel time}

Variations in travel speed have a noticeable impact on the exposure of residents (Fig. 8a) relative to calculated travel times to safety. The calculated amount of time required for all residents to evacuate tsunami-prone areas ranges from $39 \mathrm{~min}$ (assuming a "run fast" rate of $3.83 \mathrm{~m} / \mathrm{s}$ ) up to $162 \mathrm{~min}$ (assuming a "walk slow" rate of $0.91 \mathrm{~m} / \mathrm{s}$ ). At the critical threshold of $25 \mathrm{~min}$, the percentage of study-area residents $(n=9,110)$ in tsunami-prone locations ranges from $7 \%$ (run-fast assumption) to $49 \%$ (walk-slow assumption). This change in travel speed translates in a reduction of lives lost from 4,464 to 638 residents 
(a)

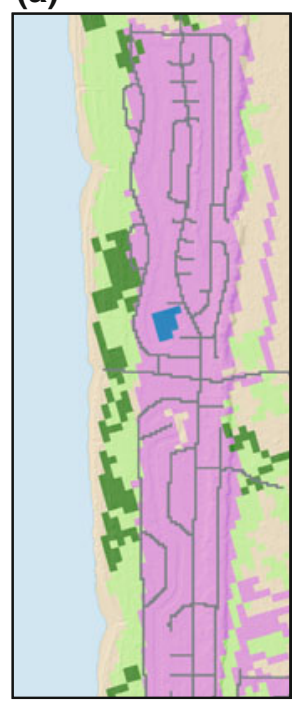

Land cover type (figures a and b)

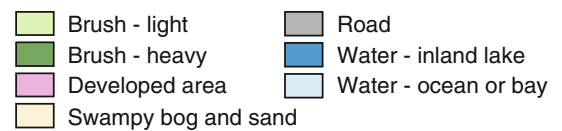

(c)

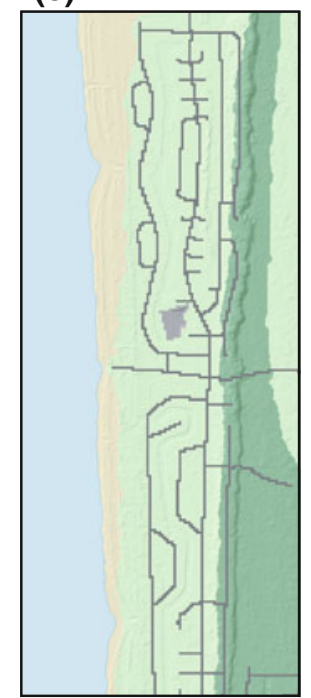

(d)

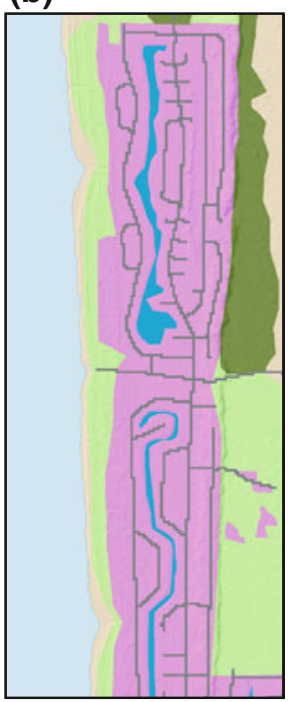

Travel time to safety in minutes (figures $\mathrm{c}$ and $\mathrm{d}$ )

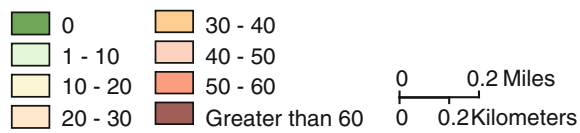

Fig. 7 Maps showing the influence of land-cover data on evacuation-modeling outputs near the community of Oysterville (Fig. 1). Land-cover input data include a NLCD data derived from 30-m LandSat TM imagery and b 1-m data derived from manual interpretation of 1-m NAIP imagery. Model outputs (travel times in $\mathrm{min}$ ) are based on an anisotropic approach using 1-m elevation data and either c 30-m NLCD data or d 1-m land-cover data

(Table 3), assuming all residents would be capable of moving at the quicker speed. Although this assumption is not realistic, these calculations do demonstrate how mortality rates can be reduced if at-risk individuals are capable of improving their travel speeds. Even small improvements in travel speeds, such as walking quickly $(1.52 \mathrm{~m} / \mathrm{s})$ instead of slowly $(0.91 \mathrm{~m} / \mathrm{s})$, could translate into 900 more people $(10 \%$ of study area) being able to evacuate tsunami-prone areas (Fig. 8a).

The impact of travel speeds on pedestrian-evacuation modeling is also apparent with employee distributions. The calculated amount of time required for all employees to evacuate tsunami-prone areas ranges from $37 \mathrm{~min}$ (fast-run assumption) to $158 \mathrm{~min}$ (slowwalk assumption) (Fig. 8b). At the critical threshold of $25 \mathrm{~min}$, the percentage of study-area employees $(n=779)$ in tsunami-prone locations ranges from $6 \%$ (run-fast assumption) to $62 \%$ (walk-slow assumption). With the three modeled walking speeds, there is not much variation in terms of employee exposure in tsunami-prone areas at the 25-min threshold, ranging from 56\% (fast-walk assumption) to $62 \%$ (slow-walk assumption) (Table 3). Dramatic changes in employee exposure at the 25 -min threshold occur when at-risk individuals are capable of increasing travel speeds from slow-walk assumptions to moderaterun assumptions. Changes are more apparent between the walking speeds at greater times, such as $35 \mathrm{~min}$ or more in travel time (Fig. 8b).

The impact of travel speeds on evacuation times for populations at public venues and dependent-care facilities is also dramatic (Table 3 ). The number of public venues 

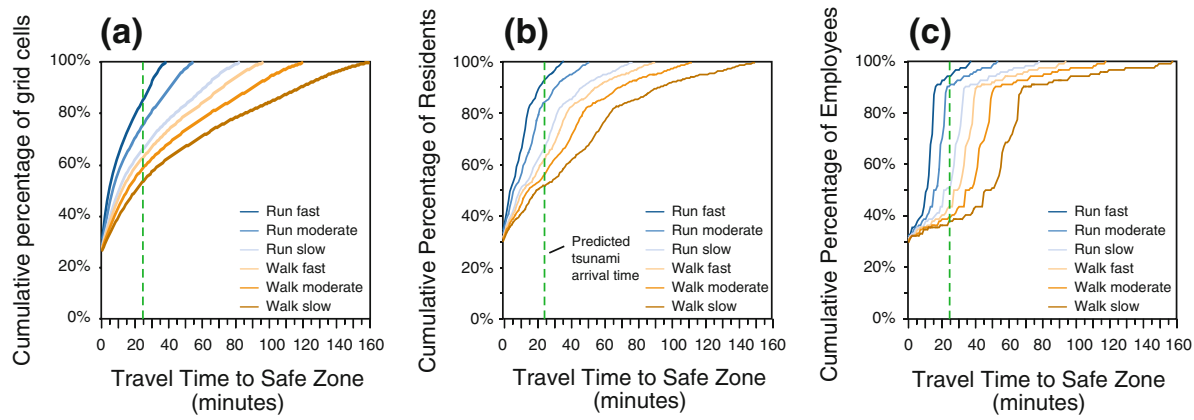

Fig. 8 Graphs showing influence of travel speeds on a the cumulative percentage of grid cells in the study area, $\mathbf{b}$ the cumulative percentage of residents $(n=9,008)$ as a function of calculated travel times to safety, and $\mathbf{c}$ the cumulative percentage of employees $(n=779)$ as a function of calculated travel times to safety

Table 3 Differences in potential population exposure to tsunamis based on travel-speed inputs to pedestrian-evacuation models

Travel speed of individuals

\begin{tabular}{llllll}
\hline $\begin{array}{l}\text { Walk } \\
\text { slow }\end{array}$ & $\begin{array}{l}\text { Walk } \\
\text { moderate }\end{array}$ & $\begin{array}{l}\text { Walk } \\
\text { fast }\end{array}$ & $\begin{array}{l}\text { Run } \\
\text { slow }\end{array}$ & $\begin{array}{l}\text { Run } \\
\text { moderate }\end{array}$ & $\begin{array}{l}\text { Run } \\
\text { fast }\end{array}$ \\
\hline
\end{tabular}

Number of people at 25 min or more travel time

$\begin{array}{lrrrrrr}\text { Residents }(n=9,110) & 4,402 & 4,067 & 3,502 & 3,120 & 1,479 & 693 \\ \text { Employees ( } n=779) & 482 & 470 & 437 & 374 & 70 & 46 \\ \text { Number of facilities at } 25 \text { min or more travel time } & 42 & 40 & 38 & 36 & 9 & 7 \\ \text { Public venues } & 7 & 7 & 6 & 6 & 2 & 1 \\ \text { Dependent-population facilities } & & & & & & \end{array}$

at locations that would require $25 \mathrm{~min}$ or more to evacuate tsunami-prone land ranges from 7 (fast-run assumption) to 42 (slow-walk assumption). The number of dependent-care facilities at locations that would require $25 \mathrm{~min}$ or more to evacuate tsunami-prone land ranges from one (fast-run assumption) to seven (slow-walk assumption). There are not substantial differences in venue and facility exposure at lower speeds (slow-walk to slowrun assumptions) (Table 3). There are considerable reductions in venue and facility exposure once individuals are capable of attaining moderate-run speeds. However, this is unrealistic, given the nature of the at-risk individuals. Tourists at hotels and other public venues may be physically capable of greater travel speeds but will likely be disoriented and will lose time as they navigate unfamiliar landscapes. Children at schools and day-care centers, as well as hospital patients, will be unable to reach these greater speeds; therefore, the use of slowest travel speeds is likely the most appropriate for these populations in future modeling efforts.

\section{Discussion}

Many coastal communities throughout the world are threatened by tsunamis that could inundate low-lying land within minutes after a devastating earthquake. Evacuation 
modeling can help at-risk individuals and emergency managers understand where evacuations may not be likely and where vertical-evacuation strategies may be warranted. Maps that characterize travel times to safety (Fig. 2a) and figures that summarize spatial variations in population exposure (Fig. 3) provide a place-based context of evacuation potential. They are important tools in communicating societal vulnerability to tsunamis to policy makers, emergency managers, and the public. Like all modeling, LCD pedestrianevacuation modeling for tsunami events is a simplified representation of reality and it rests on a series of assumptions, such as wave-arrival times, land-cover conditions, and the influence of slope on travel speeds, among others. In this section, we discuss research results in the context of the influence of modeling assumptions on determining tsunamievacuation times, how results can be used in tsunami-education efforts, and where future research is needed.

\subsection{Influence of modeling assumptions}

Results suggest that modeling slope as an anisotropic cost and allowing travel across a variable land surface creates substantial differences in estimated evacuation times compared to other modeling assumptions. Relative to the anisotropic approach, the distance and isotropic approaches consistently underestimated travel times (Fig. 2), with differences on the order of $10 \mathrm{~min}$ or less for most of the study area (isotropic) and up to $40 \mathrm{~min}$ (distance). The roads approach also varied greatly from the anisotropic approach but differences were not consistent - travel times were underestimated by $40 \mathrm{~min}$ in some areas and overestimated by the same amount in other areas (Fig. 2c). Although we found that these model differences did not have a substantial impact on estimated population at the time of wave arrival (0-14\% difference; Table 2), this result would be different with a different population distribution or wave-arrival time.

Despite the fairly low relief and open land cover in our study area, our results also indicate that evacuation models are sensitive to varying levels of resolution in elevation and land-cover data. In our study area and with this input data, models are more sensitive to changes in elevation resolution than in land-cover resolution. This sensitivity is highest in areas where evacuation times are greatest (Fig. 5), indicating the differences are cumulative across the landscape. The use of 10-m elevation data instead of 1-m data (regardless of land-cover dataset) consistently resulted in underestimates of evacuation travel time, ranging from a few minutes near the safe zone to $90 \mathrm{~min}$ at the farthest point from safety (Fig. 5d). This resulted in population exposure estimates that were 60-86\% lower than those based on the 1-m elevation data (Table 2). These results demonstrate the need for researchers to seek out and use high-resolution elevation data in future evacuation-modeling efforts. The results also provide support for the acquisition and dissemination of LiDAR data for all areas prone to near-field tsunamis. These results lead us to question the utility of developing evacuation-time maps if high-resolution elevation data are not available. In the end, precise, visually compelling maps can be made using coarse data, but their accuracy would be highly questionable.

Changes in land-cover data resolution and type did create differences in evacuation times; however, most differences were not large - typically overestimates of 1-15 min across the study area with pockets of underestimated travel times on the order of one to 30 min (Fig. 5b). Changes in land-cover resolution had minimal impact on population exposure estimates across the study area (between 0 and $5 \%$ greater than those using the 1-m data). Variations in the land-cover data had the greatest impact on estimated travel times and population exposure in areas where small water bodies were not represented in 
smaller-scale NLCD data (e.g., natural rivers east of Ilwaco and artificial canals west of Oysterville) (Fig. 7). Once these water bodies were included in the evacuation models, evacuation routes were constrained, which resulted in longer travel times. In an ideal world, researchers will have the resources and opportunity to delineate land-cover types and water boundaries using current, high-resolution imagery. Realizing that this may be unrealistic for some due to time, imagery access, or interpretation expertise, we recommend that land-cover data derived from moderate resolution imagery, such as NLCD in the United States, are updated with ancillary data characterizing water bodies (e.g., National Hydrologic Dataset) or other impediments (e.g., fences) to minimize occurrences of overor under-estimating pedestrian travel.

Underestimation of travel times is a public-safety concern if at-risk individuals think they have more time than they really do to evacuate. It also promotes a false sense of security in at-risk individuals and the emergency managers that serve them and may reduce the likelihood of communities taking action before an event to prepare. Given the long distances and short time periods to evacuate (over $4 \mathrm{~km}$ in some areas in less than $25 \mathrm{~min}$ ), even a few extra minutes to evacuate can mean the difference between life and death for many individuals. Therefore, although differences in modeled evacuation times between Anisotropic and Isotropic approaches may seem insignificant across an entire study area (Fig. 2d), there may be important local differences and an anisotropic approach that uses high-resolution elevation data and path-distance algorithms is recommended in future evacuation-modeling efforts.

While the conservative nature of evacuation analyses suggests that one would rather see a model that overestimates evacuation time than one that underestimates them, overestimation may also introduce challenges to public preparedness and outreach. Tsunamioutreach efforts that communicate overestimates of the amount of time it would take to evacuate can result in fatalistic attitudes. For example, if at-risk individuals believe it will take 40 min to evacuate to higher ground (instead of 20 min based on proper modeling assumptions) in an area where tsunami inundation is predicted in $25 \mathrm{~min}$, then they may give up any hope of trying to prepare for future events. This belief may create feelings of negative outcome expectancy, in which individuals are less likely to prepare for tsunamis because they do not think their actions (e.g., evacuation training, buying weather radios) will change the likely outcome (e.g., drowning from a tsunami) (Paton et al. 2008).

Overestimation of travel times was common using the Roads approach to model pedestrian evacuations in our study area (Fig. 2c), suggesting that the decision to model pedestrian travel along a road network versus allowing movement across the broader landscape as a whole is not trivial. In our study area, there are several places where the Roads modeling approach overestimates evacuation times by up to $40 \mathrm{~min}$ (dark green areas in Fig. 2c). At these locations, the evacuation model forces at-risk individuals to travel longer distances than needed to survive, and these additional distances may lead to greater deaths. Pedestrian evacuations should therefore be modeled over a landscape, instead of along a constrained road network, and subsequent tsunami-education efforts should discuss evacuation routes that cross open land or through neighbors' yards. This is less of a factor, however, in more urban settings, where roads may be the more efficient, and possibly only, way to represent actual movement to higher ground, given the density of buildings and fences between properties.

This issue of travel constraints due to high building densities and fences highlights the importance of understanding land-cover and landscape conditions. In addition to incorporating small water bodies, it is important to also consider the feasibility of modeled routes and route capacities given real-word land conditions which will vary from their 
geospatial interpretations. For example, an area along an evacuation route that is considered in a model to be grassland on a moderate slope may be covered in thick and thorny brambles in the summer, thereby making evacuation difficult, if not impossible. Likewise, heavy machinery, security fences, cargo containers, or fishing gear (e.g., crab pots) may constrain or block evacuation routes through coastal, non-residential areas. Therefore, fieldwork to update model inputs and to assess the feasibility of evacuation routes is an important next step in applying evacuation-modeling results at the local level. In addition, certain points on the landscape may serve as evacuation chokepoints that constrain routes or create congestion (e.g., bridges or a path through a dense forest) and the application of agent-based modeling in these situations may be warranted. Fieldwork also may suggest prescriptive management techniques such as continued landscape maintenance (e.g., mowing bramble-prone areas every week) or organized storage of heavy machinery may be cost-effective approaches to minimizing loss of life from future tsunamis.

Another notable finding of this study is the documented influence of travel speeds on evacuation routes. Although this is obvious from a conceptual standpoint, this study documents changes in population exposure based on travel speeds and in doing so, provides a mechanism for demonstrating the savings in lives if at-risk individuals increased their travel speeds. For example, if at-risk individuals across the study area were to walk quickly $(1.52 \mathrm{~m} / \mathrm{s})$ instead of slowly $(0.91 \mathrm{~m} / \mathrm{s})$ to higher ground, the number of people still in tsunami-prone areas when waves arrive would decrease by 900 residents (10\% of study area) and 45 employees (6\% of study area) (Fig. 8).

\subsection{Use of results in tsunami education}

Our focus on characterizing the tsunami-evacuation landscape can complement tsunamieducation efforts in several ways. First, results suggest that tsunami preparedness could potentially be improved if framed as a public-health issue. To date, efforts to increase individual preparedness to tsunamis have primarily come from the emergency-management community and have focused on the ability to recognize natural cues, receive warnings, and know where to run. However, results presented here demonstrate the additional lives saved if travel speeds of at-risk individuals are increased during an evacuation. Therefore, a public-health campaign that emphasized improving one's ability to walk briskly could be communicated as a way to not only reduce health concerns on a daily basis but may also save one's life in the event of a tsunami. Maps showing evacuation travel times based on various travel-speed assumptions (e.g., mapped outputs of Fig. 8) could be displayed to provide at-risk individuals with visual evidence of the importance of quicker travel speeds. At-risk individuals could be encouraged to continually practice their evacuation routes as part of a general health-improvement and exercise plan. Doing so would help individuals determine their true time requirements to reach safety and possibly provide an incentive to improve their travel speeds. Given the financial constraints of most rural, coastal communities, tsunami-preparedness efforts that leverage expertise from the public-health community may be more easily attained than securing additional financial resources for structural adaptations (e.g., vertical-evacuation structures).

Another use of evacuation-modeling results is in educating at-risk individuals on potential evacuation routes. During an evacuation, individuals are likely to use roads due to familiarity with the road network, people's unease with running through natural/wooded areas (especially if the event occurs at night) or they may try to evacuate in their cars and need to abandon them. However, modeling results indicate that evacuation times can be reduced if individuals seek higher ground by leaving a road network and going through 
their neighbors' yards or across fields. Translating this knowledge of improved evacuation routes into action and behavior change would not be a simple task, given people's preconceived perceptions of safety. Initial steps in this education process would involve gauging the knowledge of at-risk individuals on effective evacuation routes and safe areas and possibly changing the location and directional information on evacuation signage to highlight optimal routes. To account for the likelihood that many people may stick to roads during an evacuation, results of the anisotropic modeling approach could be combined with results of a roads-only modeling approach (for example, results represented as a range or with some sort of error bar).

Finally, results of evacuation-modeling efforts can be effective tools in community discussions and education efforts related to vertical-evacuation planning. Modeling results can help initiate vertical-evacuation discussions by indicating areas where horizontal evacuations to high ground may not be feasible. If there is already consensus among emergency managers and scientists that vertical evacuations may be necessary, community discussions can be held to generate greater buy-in and acceptance within an at-risk community (e.g., Engstfeld et al. 2010) and modeling results can help refine these discussions by approximating the number of potential vertical-evacuation sites that may be warranted and narrowing down a list of proposed sites to find an optimal solution. As discussed earlier, LCD outputs can help frame evacuation issues for a region and agent-based models could then be run for potential structure sites and based on specific planning scenarios for use in a structure cost-benefit analysis.

\subsection{Areas for future research}

Results from evacuation-modeling efforts are not a final statement on mortality - they are meant to help initiate and inform discussions between emergency managers, affected populations, and scientists, to assist in decision making and policy formulation, and to identify additional research avenues. One topic for further study is the interdependent nature of land condition and slope. As mentioned earlier, land-cover and slope-based SCVs were multiplied to create the final cost surface used for the LCD analysis (Anguelova et al. 2010; Laghi et al. 2006). Doing so, however, assumes that the SCV for slope and land cover are independent of one another (e.g., the impact of movement on sand versus roads will remain constant regardless of the slope on which they are found). It is likely that there is a relationship between the two and that this relationship is modified further by demographic attributes; for example, pedestrians who use some sort of assistive devices (e.g., crutches, canes, or walkers) may experience a greater decrease in SCV than others when moving from a paved to a vegetated surface on a slope.

As noted earlier, we assumed that evacuation speeds would remain constant over long distances, ignoring the influence of fatigue and that travel speeds over various land-cover types could be estimated based on Soule and Goldman's (1972) terrain energy coefficients. Research involving ground-truthing fieldwork on the actual variations in pedestrian travel speeds over relevant land-cover types, slopes, and distances would strengthen these approaches. Further work could also seek to adapt current LCD approaches to account for pedestrian fatigue over time and space, and related to variations in demographic characteristics, such as age or mobility limitations. In addition, LCD approaches described here do not account for changes in route capacity or congestion. Ideally, an approach that integrates agent-based and least-cost-distance models is preferred, in which a LCD approach is used initially to approximate travel times across an area where population 
distributions and wave-arrival times are difficult to determine precisely and accurately (such as our study area). Results of this initial approach would be useful for tsunami education and preparedness planning. An agent-based model could then be used in specific locations where congestion is likely (e.g., near bridges and confined road networks) and for specific scenarios of population distributions and wave-arrival times to support functional exercises by emergency managers and cost-benefit calculations for vertical-evacuation structures. The influence of pedestrian fatigue, the interaction of land cover and slopes, and route capacity on travel speeds could be field-tested through community evacuation exercises, done in collaboration with local emergency managers.

Another factor for future research is the time required for wave propagation across the landscape (e.g., from the west to the east side of the Long Beach Peninsula or inundation from the east via Willapa Bay). Estimates of population exposure to tsunamis throughout the paper are based on the presence of individuals in areas that would require $25 \mathrm{~min}$ or more to reach higher ground. That assumes that all locations in the study area will be inundated at the same time; however, only the coastline would be inundated at $25 \mathrm{~min}$ after the initial earthquake. Tsunami waves will take additional time to progress from west to east, which is believed to be approximately 10 miles $(\sim 16 \mathrm{~km})$ per hour (Tim Walsh, Washington Department of Natural Resources, personal communication) and inundate inland areas. Therefore, populations located further inland will likely have additional time to reach safety. Subsequent evacuation modeling should account for this delay in tsunami inundation. For this initial study on pedestrian-evacuation modeling for Cascadia tsunamis, we felt this complicating factor could be omitted because the majority of the population on the Long Beach Peninsula is located near the western shoreline and not further inland. However, for larger and more dispersed populations this factor could be significant.

Also assumed in this modeling effort are issues related to the knowledge and behavior of at-risk individuals. For instance, maps of travel times presented in this paper assume that people will initiate self-evacuations immediately after ground-shaking ends. In reality, evacuations will be delayed as individuals take time to process observed natural cues, such as prolonged ground shaking or shoreline draw-down. Many will take time to validate what they experienced with those around them or even try to call trusted individuals (e.g., friends, family, neighbors) to validate these observations (often called milling in the socialsciences literature). Still others may not move at all, unaware of the natural cues, until others walk or run by them, either providing physical cues (seeing the movement) or social cues (being told to run by others). Evacuations will also be delayed as people attempt to fulfill caregiver roles (e.g., helping children, the elderly, or pets) or reach for items they deem to be critical to their post-disaster quality of life (e.g., emergency kits, important paperwork). Important follow-up research involves understanding the pre-event knowledge base of at-risk individuals with the goal of using results to minimize the time needed for individuals to take self-protective actions. This includes gauging the ability of individuals to recognize natural cues, influences on the extent of their milling before taking action, and constraints on their ability to move.

\section{Conclusions}

This study of pedestrian-evacuation modeling for potential tsunamis focused on least-costdistance models that incorporate land-cover variations and anisotropic assumptions of 
slope directionality. Based on our analysis, we reach several conclusions that bear on future pedestrian-evacuation modeling.

1. There are substantial numbers of residents, employees, tourists at public venues, and individuals with limited mobility at dependent-population facilities in areas where evacuation by foot to natural higher ground before tsunami inundation is not feasible.

2. Deviations from an anisotropic approach using path-distance algorithms to model pedestrian evacuations substantially influence the time likely needed to reach higher ground. A distance-only approach that ignores variations in land cover and slopes greatly underestimates the time needed to evacuate. A road-constrained approach underestimates travel times in some areas but overestimates times in other areas, thereby creating an uncertain result for emergency managers. An isotropic approach that incorporates variations in land cover and elevation but ignores the directionality of slopes slightly underestimates travel times over the study area. These differences are substantial in areas where a few minutes will matter between life and death.

3. Changes in the resolution of elevation data (from 1- to 10-m grid cells) had a substantial impact across the entire study on travel times to safety and, subsequently, on the number of people that are in areas where evacuation before tsunami inundation is not feasible.

4. Changes in the resolution of land-cover data (from 1- to 30-m grid cells) greatly influenced travel times in several locations, specifically in locations with travelinhibiting waterways, but did not have a substantial impact across the entire study area. If regional land-cover datasets are to be used, then they should be updated with higherresolution data that adequately delineate water bodies or other potential obstructions to pedestrians.

5. Changes in travel-speed assumptions had a substantial impact on the population exposure estimates. Therefore, efforts to increase travel speeds via public-health campaigns may be an effective risk-reduction strategy to minimize loss of life.

These conclusions support the notion that a place-based context is important for understanding community vulnerability to natural hazards (Jones and Andrey 2007). Evacuation modeling that includes poor assumptions (e.g., straight distance or road-only travel, cost distance instead of path distance), ignores land-cover conditions and slope directionality, or blindly uses easily accessible national elevation and land-cover datasets are capable of creating precise, visually compelling, but highly inaccurate estimates of travel time for pedestrians to reach high ground. To fully understand and communicate challenges in pedestrian evacuations from tsunamis, researchers need to appreciate variations in the evacuation landscape (e.g., land-cover conditions, water bodies, slope directionality, and barriers) and in the knowledge and abilities of at-risk population. If done properly, evacuation modeling can be a powerful tool to support emergency managers in their efforts to prepare at-risk populations for future tsunamis.

Acknowledgments This study was supported by the U.S. Geological Survey (USGS) Geographic Analysis and Monitoring Program. We thank Susan Benjamin, William Forney, Ronald Kirby, and Mara Tongue of the USGS, John Schelling of the State of Washington Military Department Emergency Management Division, Patrick Corcoran of Oregon Sea Grant, Kevin Borden of Digital Sandbox, and two anonymous reviewers for their insightful reviews of earlier versions of the article. Any use of trade, product, or firm names is for descriptive purposes only and does not imply endorsement by the U.S. Government.

Open Access This article is distributed under the terms of the Creative Commons Attribution Noncommercial License which permits any noncommercial use, distribution, and reproduction in any medium, provided the original author(s) and source are credited. 


\section{References}

Anguelova Z, Stow DA, Kaiser J, Dennison PE, Cova T (2010) Integrating fire behavior and pedestrian mobility models to assess potential risk to humans from wildfires within the U.S.-Mexico border zone. Prof Geogr 62(2):230-247

Butler B, Cohen J, Putnam T, Bartlette R, Bradshaw L (2000) A method for evaluating the effectiveness of firefighter escape routes. In: Proceedings of the 2000 international wildfire safety summit, pp 42-53

Cascadia Region Earthquake Workgroup (2005) Cascadia subduction zone earthquakes-a magnitude 9.0 earthquake scenario. Oregon Department of Geology and Mineral Industries, Portland

Engstfeld A, Killebrew K, Scott C, Wiser J, Freitag B, El-Anwar O (2010) Tsunami safe haven projectreport for Long Beach, Washington. Department of Urban Design and Planning, College of Built Environments, University of Washington

ESRI (2009a) Cost distance algorithm.Available via http://webhelp.esri.com/arcgisdesktop/9.3/index.cfm? TopicName=Cost_Distance_algorithm. Accessed 9 July 2010

ESRI (2009b) Path distance: adding more cost complexity. Available at http://webhelp.esri.com/ arcgisdesktop/9.3/index.cfm?TopicName=Path_Distance:_adding_more_cost_complexity. Accessed 16 July 2010

Fitzpatrick K, Turner S, Brewer M, Carlson P, Ullman B, Trout N, Park E, Whitacre J, Lalani N, Lord, D (2006) Improving pedestrian safety at unsignalized crossings. Transit Cooperative Research Program Report 112, Transportation Research Board, Washington, DC

Fritz S, Carver S (1998) Accessibility as an important wilderness indicator-modelling Naismith's rule. School of Geography, University of Leeds. Available at http://www.geog.leeds.ac.uk/papers/list.html. Accessed 16 July 2010

Gesch D, Evans G, Mauck J, Hutchinson J, Carswell W Jr (2009) The National Map-elevation: U.S. Geological Survey Fact Sheet 2009-3053, 4

Graehl N (2009) Using a GIS to model pedestrian evacuation times for Newport, OR. Unpublished research, Humbolt State University, California

Hewett M (2005) Automating feature extraction with the ArcGIS spatial analyst extension. 2005 ESRI international users conference proceedings. Available at http://proceedings.esri.com/library/userconf/ proc05/papers/pap2109.pdf. Accessed 16 Aug 2010

InfoUSA (2010) Employer database. Available via http://www.infousagov.com/employer.asp. Accessed 1 May 2010

Italian Ministry for the Environment, Land and Sea (IM-ELS) (2006) Reduce tsunami risk: strategies for urban planning and guidelines for construction design. Department for Environmental Research and Development, in collaboration with the Asian Disaster Preparedness Center. http://www.adpc.net/ v2007/Downloads/2007/March/HANDBOOK-\%20Guidelines_for_construction_DMS_2007.zip

Jobe R, White P (2009) A new cost-distance model for human accessibility and an evaluation of accessibility bias in permanent vegetation plots in Great Smoky Mountains National Park, USA. J Veg Sci 20:1099-1109

Jones B, Andrey J (2007) Vulnerability index construction: methodological choices and their influences on identifying vulnerable neighborhoods. Int J Emerg Manag 4(2):269-295

Jonkmann S, Vrijling J, Vrouwenvelder A (2008) Methods for the estimation of loss of life due to floods: a literature review and a proposal for a new method. Nat Hazard 46:353-389

Knoblauch R, Nitzburg M, Dewar R, Templer J, Pietrucha M (1995a) Older pedestrian characteristics for use in highway design, McLean. US Department of Transportation, VA. Federal Highway Administration; Report no. FHWA-RD-93-177

Knoblauch R, Pietrucha M, Nitzburg M (1995b) Field studies of pedestrian walking speed and start-up time. In: Transportation research record, no. 1538, TRB, National Research Council, Washington, DC, pp 27-38

Laghi M, Cavalletti A, Polo P (2006) Evacuation routes tools ArcGIS toolbox user's manual. Italian Ministry for the Environment and the Territory and Asian Disaster Preparedness Center. Available via http://www.adpc.net/v2007/Downloads/2007/May/

EVACUATION\%20ROUTES\%20TOOLS\%20A5_for_print.pdf. Accessed 16 July 2010

Langlois J, Keyl P, Guralnik J, Foley D, Marottoli R, Wallace R (1997) Characteristics of older pedestrians who have difficulty crossing the street. Am J Pub Health 87:393-397

MarathonGuide.com (2011) Boston marathon race results 2010, Available at http://www.marathonguide. com/results/browse.cfm?MIDD=15100419. Accessed 8 Mar 2011

National Research Council (2011) Tsunami warning and preparedness: an assessment of the US tsunami program and the nation's preparedness efforts, Committee on the Review of the Tsunami Warning and 
Forecast System and Overview of the Nation's Tsunami Preparedness, National Research Council, $284 \mathrm{pp}$

Norman J (2004) Running uphill: energy needs and Naismith's Rule. J Oper Res Soc 55(3):308-311

Pacific County Department of Public Works (2010) County roads. Available at http://www.co.pacific.wa.us/ gis/DesktopGIS/WEB/index.html. Accessed 16 Aug 2010

Paton D, Houghton B, Gregg C, Gill D, Ritchie L, McIvor D, Larin P, Meinhold S, Horan J, Johnston D (2008) Managing tsunami risk in coastal communities-identifying predictors of preparedness. Aust J Emerg Manag 23(1):4-9

Pingel T (2009) Modeling slope as a contributor to route selection in mountainous areas. UCGIS 2009 summer assembly. Available at http://www.ucgis.org/summer2009/studentpapers/pingel_thomas.pdf. Accessed 16 July 2010

Post J, Wegscheider S, Muck M, Zosseder K, Kiefl R, Steinmetz T, Strunz G (2009) Assessment of human immediate response capability related to tsunami threats in Indonesia at a sub-national scale. Nat Hazard Earth Syst Sci 9:1075-1086

Priest G, Myers III E, Baptista A, Fleuck P, Wang K, Kamphaus R, Peterson C (1997) Cascadia subduction zone tsunamis - hazard mapping at Yaquina Bay, Oregon. Oregon Department of Geology and Mineral Industries Open-File Report O-97-34, 144

Scarf P (1998) An empirical basis for Naismith's rule. Math Today Bull Inst Math Appl 34(5):149-152

Soule R, Goldman R (1972) Terrain coefficients for energy cost prediction. J Appl Physiol 32:706-708

Tobler W (1993) Three presentations on geographical analysis and modeling-non-isotropic geographic modeling. Speculations on the geometry of geography; and global spatial analysis. UCSB. National Center for Geographic Information and Analysis Technical Report 93-1. Available at http:// www.ncgia.ucsb.edu/Publications/Tech_Reports/93/93-1.PDF. Accessed 19 July 2010

United States Census Bureau (2011) American FactFinder. Available at http://factfinder2.census.gov/faces/ nav/jsf/pages/index.xhtml. Accessed 1 May 2011

United States Department of Agriculture (2009) Geospatial data gateway. Available at http://datagateway. nrcs.usda.gov/. Accessed 1 Feb 2011

United States Department of Transportation (2009) Manual on uniform traffic control devices for streets and highways. Federal Highway Administration, 816 pp

United States Geological Survey (2008) National Land Cover Databse (NLCD 20010) multi-zone download site. Available at http://www.mrlc.gov/nlcd_multizone_map.php. Accessed 16 Aug 2010

Walsh T, Caruthers C, Heinitz A, Myers III E, Baptista A, Erdakos G, Kamphaus R (2000) Tsunami hazard map of the southern Washington coast-modeled tsunami inundation from a Cascadia subduction zone earthquake. Washington Department of Natural Resources Division of Geology and Earth Resources Geologic Map GM-49

Washington Department of Ecology (2009) Washington state marine shorelines. Available at ftp:// www.ecy.wa.gov/gis_a/shore/shore.zip. Accessed 2 Jan 2011

Washington Division of Geology and Earth Resources (2008) Tsunami inundation zones in Washington State, Version 1.0. Available at http://www.dnr.wa.gov/ResearchScience/Pages/PubData.aspx/. Accessed 16 Aug 2010

WatershedSciences (2010) LIDAR remote sensing data collection. Available at http://pugetsoundlidar. ess.washington.edu/lidardata/restricted/nonpslc/swwash2009/swwash2009.html. Accessed 16 Aug 2010

Wood N, Soulard C (2008) Variations in community exposure to tsunami hazards on the open-ocean and Strait of Juan de Fuca coasts of Washington. USGS Scientific Investigations Report 2008-5004, 34

Yeh H, Fiez T, Karon J (2009) A comprehensive tsunami simulator for Long Beach Peninsula phase-1framework development final report. State of Washington Military Department Emergency Management Division 